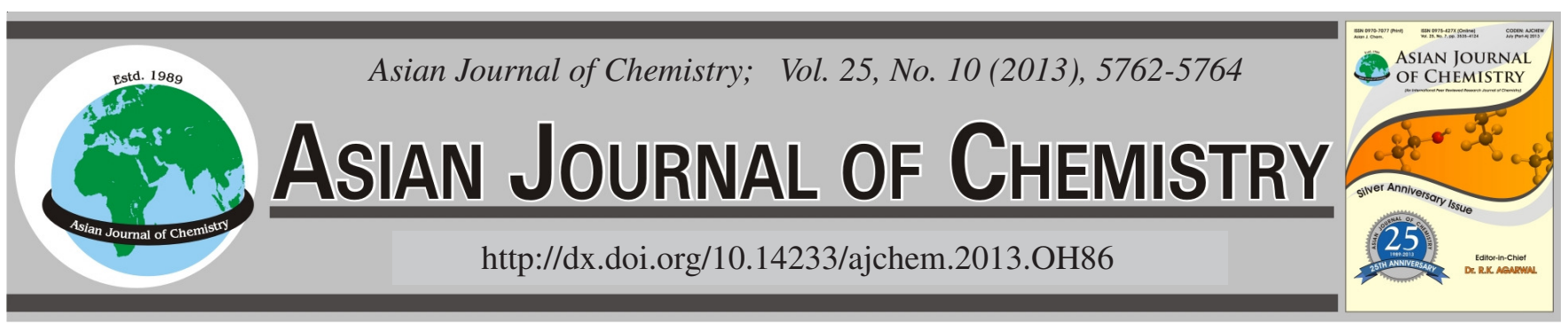

\title{
Preparation of Cyclodextrin-Modified Multi-Walled Carbon Nanotubes Through Acylamide Bond and Its Application in Capturing $\beta$-Naphthol from Wastewater $\dagger$
}

\author{
XiaO-Jie Song ${ }^{1}$, Fan Yang $^{3}$, XIAn-Wen Wei $^{2, *}$, Xian-Biao Wang $^{1}$ and Chen-Guang She ${ }^{1}$
}

${ }^{1}$ School of Materials and Chemical Engineering, Anhui University of Architecture, Hefei 230601 P.R. China

${ }^{2}$ College of Chemistry and Materials Science, Anhui Normal University, Wuhu 241000, P.R. China

${ }^{3}$ Department of Chemistry, Anhui Medical University, Hefei 230032, P.R. China

*Corresponding author: E-mail: xwwei@mail.ahnu.edu.cn

AJC- 13328

\begin{abstract}
Multi-walled carbon nanotubes (MWNTs) were covalently modified with water-soluble $\beta$-cyclodextrin ( $\beta$-CD) through acylamide bond. The products cyclodextrin modified multi-walled carbon nanotubes [MWNTs-CO-NH- $\left(\mathrm{CH}_{2}\right)_{2}-\mathrm{NH}-\mathrm{CD}$ ] were characterized by ${ }^{1} \mathrm{H}$ NMR, FT-IR spectroscopy and thermogravimetric analysis. The solubility of MWNTs-CO-NH- $\left(\mathrm{CH}_{2}\right)_{2}-\mathrm{NH}-\mathrm{CD}$ in water was $336.4 \mathrm{mg} / \mathrm{L}$ and no precipitates were observed after 18 months. The fluorescence spectra proved that the MWNTs-CO-NH- $\left(\mathrm{CH}_{2}\right)_{2}-\mathrm{NH}-\mathrm{CD}$ as a spectral probe can be used in the molecular recognition of $\beta$-naphthol $(\beta-\mathrm{NOH})$ and the effective association constant $(\mathrm{Ka})$ was calculated $1.27 \times 10^{4}$ from fluorescence spectra. By centrifugated, the $\beta$-naphthol could be separated from MWNTs-CO-NH- $\left(\mathrm{CH}_{2}\right)_{2}-\mathrm{NH}-\mathrm{CD}$, collected and reused circularly. The results showed that the MWNTs-CO-NH- $\left(\mathrm{CH}_{2}\right)_{2}-\mathrm{NH}-\mathrm{CD}$ can be used to capture the aromatic pollutant such as $\beta$-naphthol from wastewater. This study widened the application of nanosupramolecule materials.
\end{abstract}

Key Words: Carbon nanotubes, $\beta$-Cyclodextrin, Acylamide bond, Molecular recognition, $\beta$-Naphthol. ᄂ - - - - - - - - - - - - - - - - - - - - - - - - - - - -

\section{INTRODUCTION}

Since the discovery of carbon nanotubes in $1991^{1}$, they have attracted more and more attention in physical, chemical and material science fields ${ }^{2,3}$ due to their unique characteristic such as high electrical conductivity, chemical stability and high mechanical strength and modulus ${ }^{4}$. For practical applications, the aggregation of pristine carbon nanotubes which greatly decreases the efficiency of carbon nanotubes usage should be overcome $e^{5,6}$. Therefore, the chemical modifications on the surface of carbon nanotubes with small hydrophilic molecules open the door for solving the above-mentioned problem and the different strategies of chemical modification of carbon nanotubes can be further referred in a recent review ${ }^{7}$. Because of good solubility in water, $\beta$-cyclodextrin ( $(B-C D)$ was chosen to be introduced on the surface of multi-walled carbon nanotubes to enhance the solubility of multi-walled carbon nanotubes.

In this study, the aim was to modify the multi-walled carbon nanotubes with $\beta$-cyclodextrin through acylamide bond ${ }^{8}$. This compound was tried to be used in capturing aromatic pollutant in wastewater such as $\beta$-naphthol.

\section{EXPERIMENTAL}

Modification of MWNTs with $\boldsymbol{\beta}$-cyclodextrin: $2.02 \mathrm{~g}$ MWNTs were added into a mixed solution of $25 \mathrm{~mL}$ nitric acid and $75 \mathrm{~mL}$ sulfuric acid. The mixture was ultrasonicated for $20 \mathrm{~min}$ at $50{ }^{\circ} \mathrm{C}$. The acid-treated MWNTs were collected by filtration, washed with deionized water for several times until neutral and dried at $70{ }^{\circ} \mathrm{C}$ overnight.

The MWNTs-COOH and $20 \mathrm{~mL}$ thionyl chloride were mixed in a flask and refluxed for $24 \mathrm{~h}$ at $70{ }^{\circ} \mathrm{C}$ with stirring. The acyl chloride functionalized MWNTs (MWNTs-COCl) was collected by filtration, washed with anhydrous tetrahydrofuran for several times and dried in vacuum oven. The aim of this process was the introduction of acyl chloride groups on the surface of MWNTs.

$\beta$-CDOTs were synthesized in alkalescence solution as reported ${ }^{9} .{ }^{1} \mathrm{H}$ NMR $\left(300 \mathrm{MHz}, \mathrm{D}_{2} \mathrm{O}\right) \delta: 3.42-3.82(8 \mathrm{H}, \mathrm{m})$, 4.49-4.96 (2H, m), 7.43-7.46 (1H, d, J = 8.10 Hz), 7.12- 7.14 $(1 \mathrm{H}, \mathrm{d}, \mathrm{J}=7.82 \mathrm{~Hz}) .2 .0 \mathrm{~g} \beta$-CDOTs, $0.025 \mathrm{~g} \mathrm{KI}$ and ethylenediamine were added into $5 \mathrm{~mL}$ NMP in turn. This solution was stirred at $70{ }^{\circ} \mathrm{C}$ for $8 \mathrm{~h}$ in dark. The light yellow solution was cooled down to room temperature and diluted with ethanol, 
then resultant precipitate was collected by filtration, washed successively with ethanol and diethyl ether and dried under vacuum. The product $\mathrm{NH}_{2}\left(\mathrm{CH}_{2}\right)_{2}-\mathrm{NH}-\mathrm{CD}$ was obtained as reported ${ }^{8}$.

$\mathrm{NH}_{2}\left(\mathrm{CH}_{2}\right)_{2}$-NH-CD was dissolved into $20 \mathrm{~mL}$ DMF. The MWNTs-COCl was dispersed into this solution with aid of ultrasonic agitation. The mixture was stirred under Ar atmosphere at ambient temperature for $24 \mathrm{~h}$. The $\beta$-cyclodextrin modified MWNTs (MWNTs-CO-NH- $\left(\mathrm{CH}_{2}\right)_{2}-\mathrm{NH}-\mathrm{CD}$ ) was collected by filtration, washed with DMF, dried in vaccum at ambient temperature. ${ }^{1} \mathrm{H} \mathrm{NMR}\left(300 \mathrm{MHz}, \mathrm{D}_{2} \mathrm{O}\right) \delta: 0.92-1.21$ $(1 \mathrm{H}, \mathrm{m}), 1.92(4 \mathrm{H}, \mathrm{s}), 2.58-2.68(1 \mathrm{H}, \mathrm{m}), 3.25-3.74(5 \mathrm{H}, \mathrm{m})$, 4.44-4.83 $(1 \mathrm{H}, \mathrm{m})$.

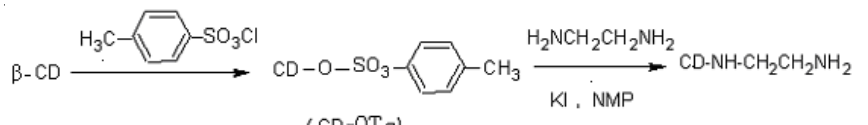
$(\mathrm{CD}-\mathrm{OTs})$

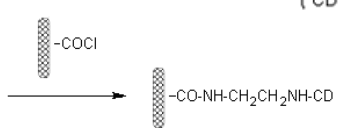

Scheme-I: Synthesis of $\beta$-cyclodextrin modified MWNTs through acylamide bond

Preparation of complex of $\beta$-naphthol and MWNTsCO-NH- $\left(\mathrm{CH}_{2}\right)_{2}$-NH-CD: $2 \times 10^{-6} \mathrm{~mol} / \mathrm{L}$ solution of $\beta$-naphthol $(\mathrm{NOH})$ was prepared. A certain amount of new MWNTs-CO$\mathrm{NH}-\left(\mathrm{CH}_{2}\right)_{2}-\mathrm{NH}-\mathrm{CD}$ was added into it, the mixture was stirred for $2 \mathrm{~h}$ to form the complex for study.

\section{RESULTS AND DISCUSSION}

Fourier transform infrared spectroscopy: In curve b (Fig. 1), the broad peak at $3417 \mathrm{~cm}^{-1}$ was assigned to the $-\mathrm{OH}$ stretching vibration, the peak at $2927 \mathrm{~cm}^{-1}$ was assigned to $-\mathrm{CH}_{2}$ - stretching vibration, the peak at $1645 \mathrm{~cm}^{-1}$ was assigned to $\mathrm{C}=\mathrm{O}$ stretching vibration, the peak at $1160 \mathrm{~cm}^{-1}$ was assigned to $\mathrm{C}-\mathrm{O}-\mathrm{C}$ asymmetric vibration and the peaks at $1027 \mathrm{~cm}^{-1}$ and $1080 \mathrm{~cm}^{-1}$ were corresponding to C-O/C-C stretching vibration. These peaks were the characteristic adsorption peaks of $\beta$ cyclodextrin and these characteristic peaks all appeared in spectrum of MWNTs-CO-NH- $\left(\mathrm{CH}_{2}\right)_{2}-\mathrm{NH}-\mathrm{CD}$ (curve c).

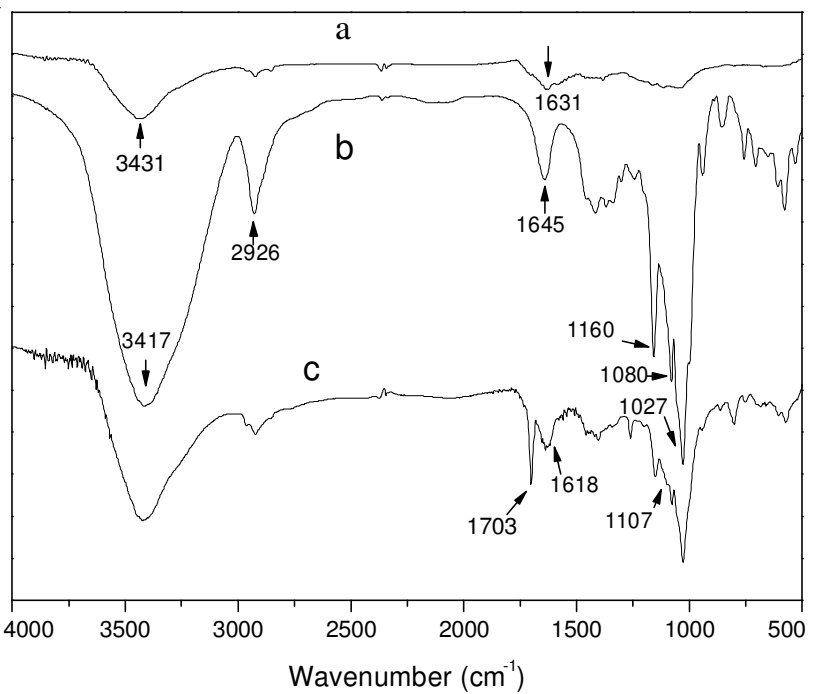

Fig. 1. FT-IR spectra of (a) MWNTs-COOH (b) $\beta$-cyclodextrin and (c) MWNTs-CO-NH- $\left(\mathrm{CH}_{2}\right)_{2}-\mathrm{NH}-\mathrm{CD}$
In curve a, the broad peak at $3431 \mathrm{~cm}^{-1}$ was assigned to the $-\mathrm{OH}$ stretching vibration, the peak at $1631 \mathrm{~cm}^{-1}$ was assigned to the $\mathrm{C}=\mathrm{O}$ stretching vibration. These characteristic peaks illustrated that carboxyl groups were introduced on MWNTs.

The spectra of $\beta$-cyclodextrin and MWNTs-CO-NH$\left(\mathrm{CH}_{2}\right)_{2}-\mathrm{NH}-\mathrm{CD}$ were quite alike, the difference was the appearance of peaks at $1703 \mathrm{~cm}^{-1}, 1618 \mathrm{~cm}^{-1}, 1107 \mathrm{~cm}^{-1}$ in spectrum of MWNTs-CO-NH- $\left(\mathrm{CH}_{2}\right)_{2}-\mathrm{NH}-\mathrm{CD}$. The peak at 1703 corresponded to the stretching vibration of $\mathrm{C}=\mathrm{O}$ groups and the subtle shift was due to the link of amino groups. The peak at 1107 was assigned to the $\mathrm{C}-\mathrm{N}$ stretching vibration; the peak at 1618 was corresponding to the $\mathrm{N}-\mathrm{H}$ stretching vibration. All these characteristic peaks showed that the $\beta$-cyclodextrin was introduced on the surface of MWNTs through acylamide bond.

Thermogravimetric analysis: Fig. 2 demonstrated the thermogravimetric analysis results of $\beta$-cyclodextrin and MWNTs-CO-NH- $\left(\mathrm{CH}_{2}\right)_{2}-\mathrm{NH}-\mathrm{CD}$. The experiment carried out in nitrogen atmosphere with a heating rate $10{ }^{\circ} \mathrm{C} / \mathrm{min}$. The weight loss was due to the decomposition of $\beta$-cyclodextrin in curve a. In curve b, the initial weight loss should be evaporation of water, the main weight loss region was from 180 to $340^{\circ} \mathrm{C}$ and the weight almost kept constant after $340^{\circ} \mathrm{C}$. This was mainly attributed to the decomposition of $\beta$-cyclodextrin in MWNTs-CO-NH- $\left(\mathrm{CH}_{2}\right)_{2}-\mathrm{NH}-\mathrm{CD}$.

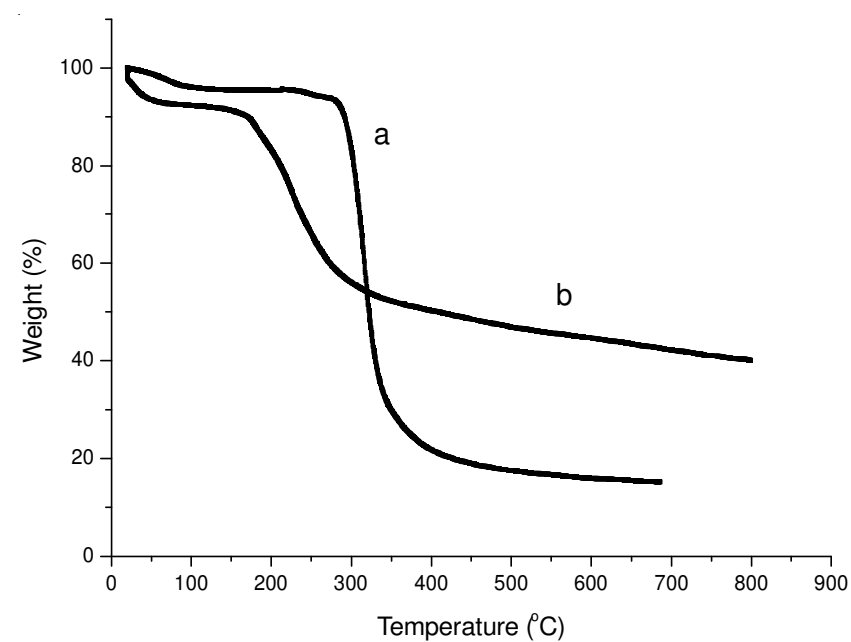

Fig. 2. TGA curves of (a) recrystallized $\beta$-cyclodextrin (b) MWNTs-CO$\mathrm{NH}-\left(\mathrm{CH}_{2}\right)_{2}-\mathrm{NH}-\mathrm{CD}$

Fluorescence spectra: Fig. 3 shows the fluorescence spectra of $\beta$-naphthol $\left(2 \times 10^{-6} \mathrm{~mol} / \mathrm{L}\right)$ in the presence of different concentration of MWNTs-CO-NH- $\left(\mathrm{CH}_{2}\right)_{2}-\mathrm{NH}-\mathrm{CD}$ at ambient temperature. The trends of curve showed that with the increase of concentration of MWNTs-CO-NH- $\left(\mathrm{CH}_{2}\right)_{2}-\mathrm{NH}-$ $\mathrm{CD}$, the fluorescence intensity decreased constantly. These results indicated that the reduction of fluorescence intensity was due to the introduction of $\beta$-naphthol into cyclodextrin cavities and the formation of inclusion complex between $\beta$ naphthol and MWNTs-CO-NH- $\left(\mathrm{CH}_{2}\right)_{2}-\mathrm{NH}-\mathrm{CD}$.

Effective association constant $\left(\mathrm{K}_{\mathrm{a}}\right)$ could be calculated from the following equation (1). $\mathrm{I}_{0}$ was the fluorescence intensity of single $\beta$ - $\mathrm{NOH}\left(2 \times 10^{-6} \mathrm{~mol} / \mathrm{L}\right)$, I was the fluorescence intensity of $\beta$-NOH $\left(2 \times 10^{-6} \mathrm{~mol} / \mathrm{L}\right)$ in presence of different concentration of MWNTs-CO-NH- $\left(\mathrm{CH}_{2}\right)_{2}-\mathrm{NH}-\mathrm{CD}$. 


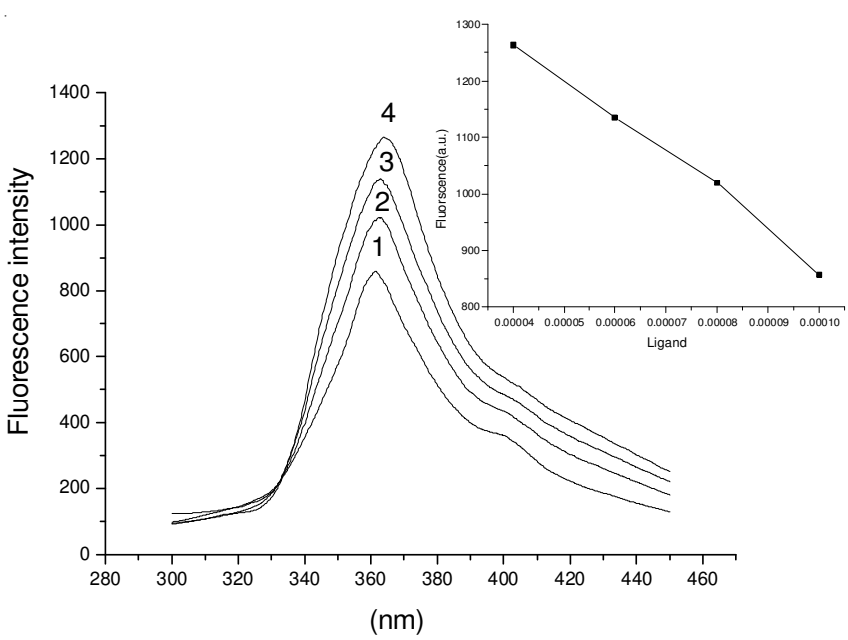

Fig. 3. Fluorescence spectra of $\beta-\mathrm{NOH}\left(2 \times 10^{-6} \mathrm{~mol} / \mathrm{L}\right)$ in the presence of different concentration of MWNTs-CO-NH- $\left(\mathrm{CH}_{2}\right)_{2}-\mathrm{NH}-\mathrm{CD}$. The excitation wavelength was $235 \mathrm{~nm}$.(From curve 4 to curve 1 , the concentration of MWNTs-CO-NH- $\left(\mathrm{CH}_{2}\right)_{2}-\mathrm{NH}-\mathrm{CD}$ were $1 \times 10^{-4}, 8$ $\times 10^{-5}, 6 \times 10^{-5}, 4 \times 10^{-5}$ respectively)

$$
\begin{gathered}
\mathrm{Y}=1-\{[(1 / \mathrm{K})+\mathrm{x}+\mathrm{S}-([(1 / \mathrm{K})+\mathrm{x}+\mathrm{S}] \\
[(1 / \mathrm{K})+\mathrm{x}+\mathrm{S}]-4 \mathrm{xS})] /(2 \mathrm{~S})\}^{1 / 2}
\end{gathered}
$$

$\mathrm{S}=[\mathrm{NOH}], \mathrm{K}=\mathrm{K}_{\mathrm{a}}, \mathrm{x}=\left[\mathrm{MWNT}-\mathrm{CO}-\mathrm{NH}-\left(\mathrm{CH}_{2}\right)_{2}-\mathrm{NH}-\mathrm{CD}-\right.$ $\mathrm{NOH}], \mathrm{Y}=\mathrm{I} / \mathrm{I}_{0}$

$\mathrm{K}_{\mathrm{a}}\left(1.27 \times 10^{4}\right)$ for inclusion complex of MWNTs-CO$\mathrm{NH}-\left(\mathrm{CH}_{2}\right)_{2}-\mathrm{NH}-\mathrm{CD}$ and $\beta$-naphthol calculated by above equation was higher than that for $\beta-\mathrm{CD}$ and $\beta$-naphthol (3.02 $\left.\times 10^{3}\right)$. Although a number of interactions were involved between MWNTs-CO-NH- $\left(\mathrm{CH}_{2}\right)_{2}$-NH-CD and $\beta$-naphthol, the most important were van der Waals interaction and hydrophobic interactions.

As displayed in Fig. 4, the $\beta$-naphthol molecules were introduced into cavities of cyclodextrin moieties to form complex. When $\beta$-naphthol molecules were included into the cavities of cyclodextrin moieties, the hydorphibic interaction were formed between $\beta$-naphthol and cyclodextrin. The molecular recognition of $\beta$-naphthol was attributed to cyclodextrin linked up with MWNTs, which may widen the application of nanosupramolecule materials and can be used to capture the aromatic pollutant such as $\beta$-naphthol from wastewater. Then, by centrifugated, the $\beta$-naphthol could be separated from MWNTs-CO-NH- $\left(\mathrm{CH}_{2}\right)_{2}-\mathrm{NH}-\mathrm{CD}$, recovered and used circularly ${ }^{11}$.
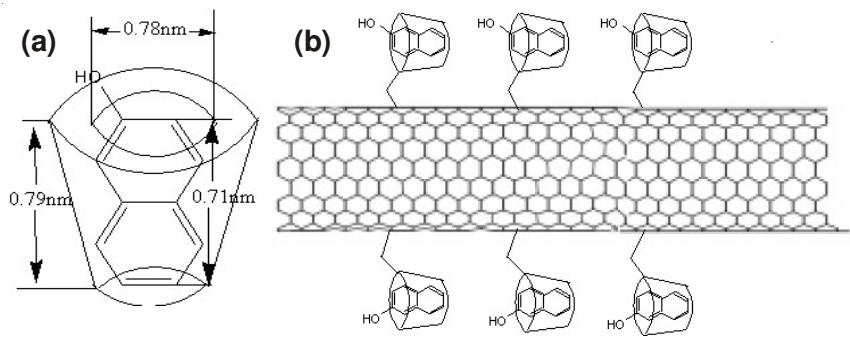

Fig. 4. (a) The interaction of $\beta$-naphthol with $\beta$-CD; (b) The schematic interaction of MWNTs-CO-NH- $\left(\mathrm{CH}_{2}\right)_{2}-\mathrm{NH}-\mathrm{CD}$ with $\beta$-naphthol

\section{Conclusion}

MWNTs were successfully modified with water-soluble $\beta-\mathrm{CD}$ through acylamide bond. The synthesis of MWNTs$\mathrm{CO}-\mathrm{NH}-\left(\mathrm{CH}_{2}\right)_{2}-\mathrm{NH}-\mathrm{CD}$ was characterized by FTIR spectra, TGA and ${ }^{1} \mathrm{H}$ NMR, the solubility of MWNTs-CO-NH- $\left(\mathrm{CH}_{2}\right)_{2}-$ $\mathrm{NH}-\mathrm{CD}$ in water was about $336.4 \mathrm{mg} / \mathrm{L}$. The MWNTs-CO$\mathrm{NH}-\left(\mathrm{CH}_{2}\right)_{2}-\mathrm{NH}-\mathrm{CD}$ powder was dispersed in water well and no precipitates were observed. This dispersion situation was last for 18 months. The $\beta$-naphthol can be included into cyclodextrin cavities of MWNTs-CO-NH- $\left(\mathrm{CH}_{2}\right)_{2}-\mathrm{NH}-\mathrm{CD}$ to form inclusion complex. The result was proved by fluorescence spectra. By centrifugated, the $\beta$-naphthol could be separated from MWNTs-CO-NH- $\left(\mathrm{CH}_{2}\right)_{2}-\mathrm{NH}-\mathrm{CD}$, recovered and used circularly easily. This study may widen the application of water-soluble MWNTs-based nanosupramolecules and capture the aromatic pollutant such as $\beta$-naphthol from wastewater.

\section{ACKNOWLEDGEMENTS}

This work was supported by National Natural Science Foundation (No. 21071005) and National Natural Science Foundation for Young Scholars (No. 21001002).

\section{REFERENCES}

1. S. Iijima, Nature, 354, 56 (1991).

2. Y.P. Sun, K. Fu, Y. Lin and W. Huang, Acc. Chem. Res., 35, 1096 (2002).

3. P. Avouris, Acc. Chem. Res., 35, 1026 (2002).

4. P.M. Ajayan, Chem. Rev., 99, 1787 (1999).

5. M. Wu, G.Z. Yang, M. Wang, W.Z. Wang, W.D. Zhang, J.C. Feng and T.X. Liu, Mater. Chem. Phys., 109, 547 (2008).

6. F.H. Wang, T.C. Lin, S.D. Tzeng and C.T. Chou, Appl. Surf. Sci., 256, 7600 (2010).

7. N. Karousis and N. Tagmatarchis, Chem. Rev., 110, 5366 (2010).

8. R.P. Bonomo, V. Cucinotta, F. D'Alessandro, G. Impellizzeri, G. Maccarrone, G. Vecchio and E. Rizzarelli, Inorg. Chem., 30, 2708 (1991).

9. B.L. May, S.D. Kean, C.J. Easton and S.F. Lincoln, J. Chem. Soc. Perkin Trans. I, 3157 (1997).

10. F.T. Tat, Z.G. Zhou, S. MacMahon, F. Song, A.L. Rheingold, L. Echegoyen, D.I. Schuster and S.R. Wilson, J. Org. Chem., 69, 4602 (2004).

11. S.L. Zhang, Z. Du and G.K. Li, Anal. Chem., 83, 7531 (2011). 